\title{
Anti-cancer effects of grailsine-al-glycoside isolated from Rhizoma Sparganii
}

\author{
Jun-Wu Zhang ${ }^{1,2}$ and Ya-Hui Wei ${ }^{*}$
}

\begin{abstract}
Background: An embryonic toxicity of Rhizoma sparganii was observed in mice. This study was aimed to evaluate the anticancer effects of Grailsine-Al-glycoside, the bioactive component of Rhizoma sparganil, on estrogen receptor-positive $\left(E R^{+}\right)$and estrogen receptor-negative $\left(E R^{-}\right)$cancer cell lines.

Methods: After A549, HeLa, HepG-2 and MCF-7 cells were treated with Grailsine-Al-glycoside, cell proliferation was analyzed by MTT, cell cycle and apoptosis by flow cytometry, and morphology with an ingmunofluorescence microscope.

Results: Grailsine-Al-glycoside strongly suppressed cell proliferation in a dose-dependent fashion in A549, MCF-7, HepG2, and HeLa cells, though this growth inhibitory effect on HepG2 cells was. not as strong and long lasting. Compared to the control, Grailsine-Al-glycoside caused a significant indrease, of apoptosis in A549, MCF-7 and Hela cells. A549 and MCF-7 cells were arrested at the G2/S phase whereas Heper2 cells were arrested at the G1 phase by a high concentration of Grailsine-Al-glycoside. Cell shapes were also changed by the presence of Grailsine-Al-
\end{abstract} glycoside.

Conclusions: Grailsine-Al-glycoside from Rhizoma sparganii inhibited the proliferation of ER ${ }^{+}$and some ER cancer cells. Grailsine-Al-glycoside may be used as a chemotherapeutic agent against ER ${ }^{+}$and ERRa-expressing $\mathrm{ER}^{-}$cancers.

Keywords: Grailsine-Al-glycoside, Rhizoma sparganii, Estrogen receptor-positive, Estrogen-related receptor alpha

\section{Background}

It is well known that many cancers have a number of receptors that are suitable targets for therapy. In particular, anti-estrogen therapy is a highly effective treatment for patients with estrogen receptor-positive $\left(\mathrm{ER}^{+}\right)$breast cancer, emphasizing the central role of estrogen activity in the development of this disease [1]. Estrogen-estrogen receptor complexes can bind directly to specific sequences of DNA, mediate transcription (gene expression), and affect various biological actions [2,3]. Proliferation of a subset of breast, lung, and hiver cancers is reportedly mediated through the estrogen-estrogen receptor mechanism [4-8].

The dried rhizome of Sparganium stoloniferum Buch.Ham. (Rhizoma Sparganii, RS) is frequently used in traditional Chinese medicine. An aqueous extract of $\mathrm{RS}(\mathrm{BS}-\mathrm{W})$ is widely used in the treatment of blood

\footnotetext{
* Correspondence: weiyahui@nwu.edu.cn

${ }^{1}$ Key Laboratory of Resource Biology and Biotechnology in Western China, College of Life Science, Northwest University, 229 Taibai Road (N), Xi'an 710069, P.R. China

Full list of author information is available at the end of the article
}

stasis, amenorrhea, functional dyspepsia, and early stages of tumors especially for hysteromyoma in China [9]. A new N-heterocyclic Al complex glycoside, Grailsine-Alglycoside, was isolated from RS-W by column chromatography and its structure was determined by spectroscopic methods (Figure 1) [10].

RS is contraindicated during pregnancy and during profuse menstrual flow. RS-W also showed anti-estrogenic and anti-angiogenesis effects in the reproductive system of rodents (unpublished data, Wei et al). Pregnant mice receiving RS showed reduced fibroblast growth factor (FGF) protein level but enhanced toxicity to $\mathrm{ER}^{+}$cells in the embryos during mice embryonic development. As embryos and tumors share many similarities in endocrine, angiogenesis, and gene expression profile, we hypothesize that RS-W may exert a anti-tumor effect on $\mathrm{ER}^{+}$tumors through similar anti-estrogen/anti-angiogenic activity. This study was intended to determine the anticancer activities of Grailsine-Al-glycoside from RS-W on $\mathrm{ER}^{+}$

\section{Biomed Central}

(c) 2014 Zhang and Wei; licensee BioMed Central Ltd. This is an Open Access article distributed under the terms of the Creative Commons Attribution License (http://creativecommons.org/licenses/by/2.0), which permits unrestricted use, distribution, and reproduction in any medium, provided the original work is properly credited. 


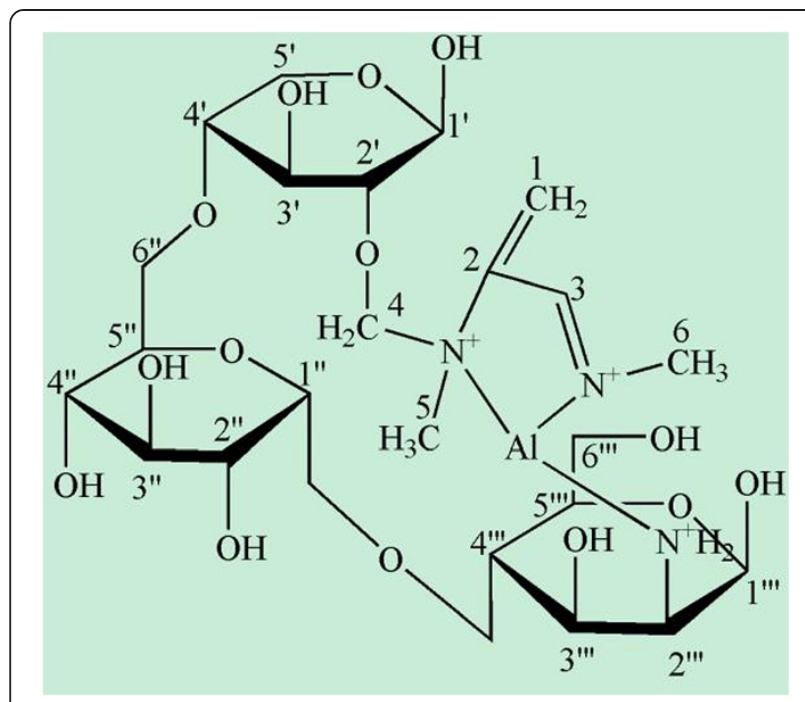

Figure 1 The chemical structure of Grailsine-Al-glycoside.

cancer cell lines, A549 and MCF-7, and ER ${ }^{-}$cancer cell lines, HeLa, and HepG-2.

\section{Methods}

\section{Extracting grailsine-Al-glycoside}

The dried herb, Sparganium stoloniferum (Rhizoma Sparganii, RS) was purchased from Yi-Kang Chain Medicine Co. (Xi'an, China). Standardization of this Arug was consistent with the regulations of the State Food and Drug Administration. The pure compound GrailsineAl-glycoside (Figure 1) was purified from aqueous extract of RS (RS-W) through the silica gel $\left(\mathrm{SiO}_{2} ; 230-\right.$ 400 mesh, Merck, Shanghai, China) and Sephadex G-25 (Sigma, St. Louis, MO) column chromatography [10]. ${ }^{3} \mathrm{H}$ and ${ }^{13} \mathrm{C}$ spectra were recorded on a Varian INOVA$400 \mathrm{MHz}$ system (Varian, Palo Alto, CA). TOF-MS spectra were obtained on an AXIMA-CFR ${ }^{\text {Tw }}$ plus MALDITOF Mass Spectrometer (SHIMADZU, Beijing, China). Elements were analyzed on a Vario EL III (Elementar Analysensysteme GmbH, Hanau, Germany), and monosaccharide composition was analyzed using the general method.

\section{Cell culture and MTT assay}

A549, Hela, HepG2, and MCF-7 were purchased from American Type Culture Collection (Manassas, VA) and maintained in DMEM plus $10 \%$ FBS at $37^{\circ} \mathrm{C}$ with $5 \%$ $\mathrm{CO}_{2}$. Cells were seeded in 96-well plates (2000 cells per well) for $4 \mathrm{~h}$ before being treated with different concentrations of Grailsine-Al-glycoside (at a final concentration of 10,20 , or $40 \mu \mathrm{g} / \mathrm{ml}$ ) for 3 days. Every $24 \mathrm{~h}$, $10 \mu \mathrm{g} / \mathrm{ml}$ of 3-(4,5-dimethylthiazol-2-yl)-2,5-diphenyltetrazolium bromide (MTT) was added into 6 wells of the cultured cells and incubated for $4 \mathrm{~h}$ protected from light sources. The MTT-treated cells were solubilized and measured at $570 \mathrm{~nm} / 630 \mathrm{~nm}$.

\section{Flow cytometry ( $\mathrm{FCM}$ ) test}

Cells were treated for $36 \mathrm{hr}$ with Grailsine-Al-glycoside before being fixed with methyl alcohol and stained with propidium iodide. DNA content was determined by flow cytometry (EPICS ${ }^{\circledR} \mathrm{XL}$, Beckman Coulter, Brea, CA), and the data was analyzed with FlowJo 5.7.2.

\section{Cell morphology}

After $12 \mathrm{hr}$ treatments, cells were fixed and stained with anti- $\alpha$-tubulin monoclonal antibody (1:1000 dilution, Sigma, St. Louis, MO, USA) overnight at $4^{\circ} \mathrm{C}$, then incubated with 1:200 diluted fluorescein-conjugated affinipure goat anti-mouse IgG (Jackson ImmunoResearch, West Grove, PA) at $37^{\circ} \mathrm{C}$ for $1 \mathrm{~h}$. Nuclei were counterstained

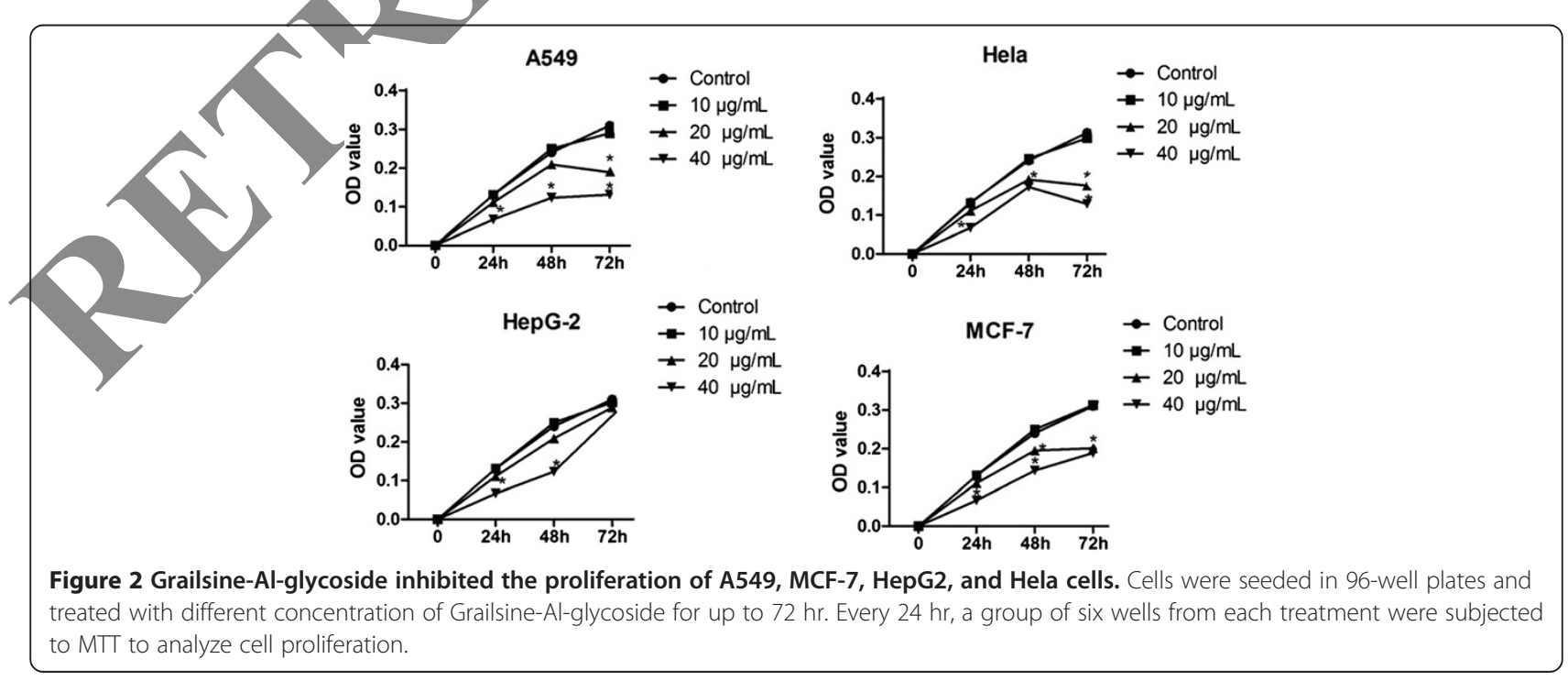



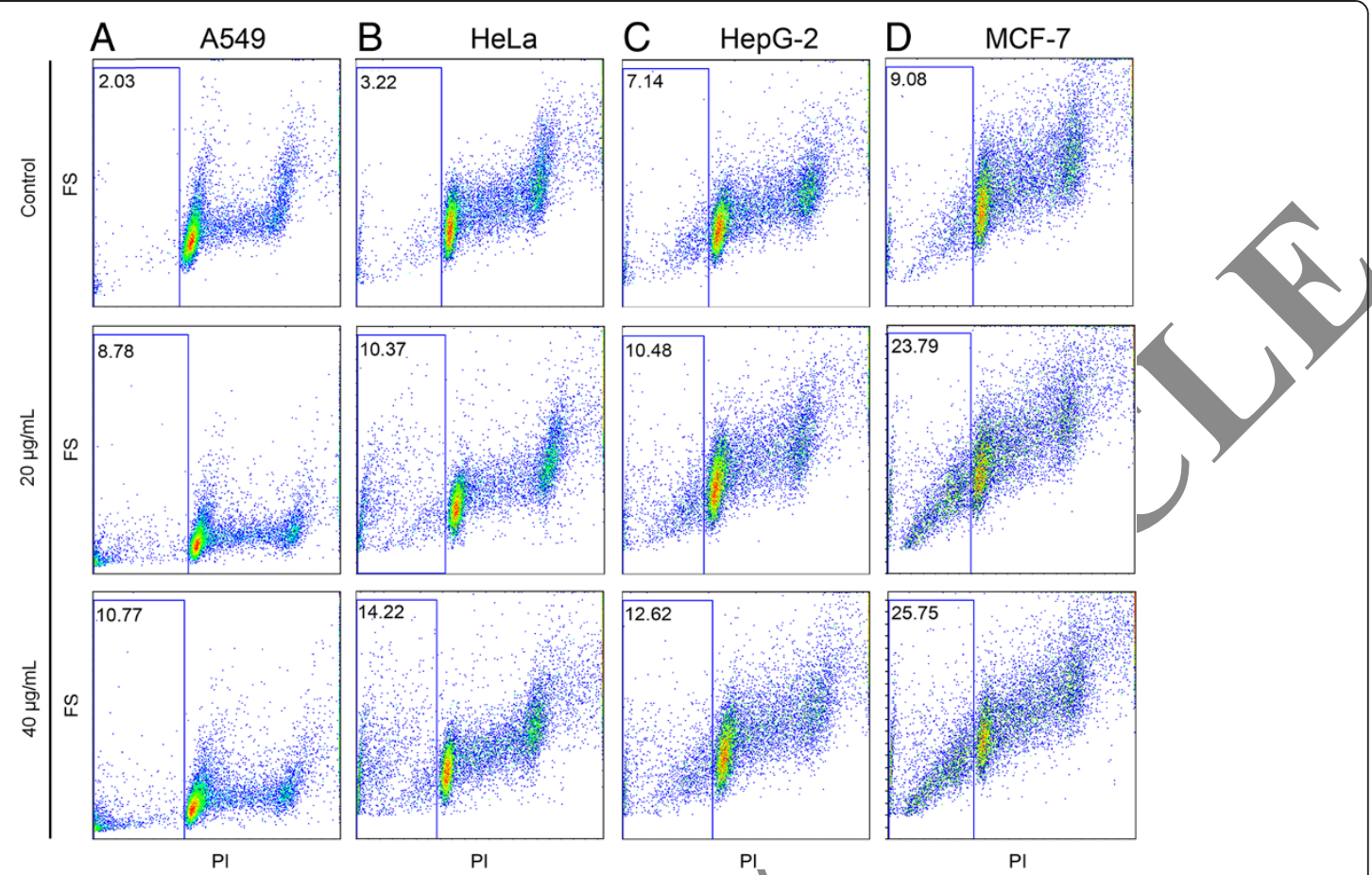

$\mathrm{PI}$

$\mathrm{PI}$

Figure 3 Grailsine-Al-glycoside triggered significant apoptosis in A549, MCF-7, and Hela cells. Cells treated with different concentration of Grailsine-Al-glycoside for 36 hrs before stained with propidium iodide and underwent flow cytometry analysis. The apoptotic cells were measured by sub-G1 population. Grailsine-Al-glycoside induced over 2 fold increase of apoptosis in A549 (A), Hela (B), and MCF-7 (D) cells but moderate increase in HepG2 cells (C)

with $1 \mu \mathrm{g} / \mathrm{ml}$ of DAPI (D9542, Sigma) at room temperature for $10 \mathrm{~min}$. The morphology of cells was examined and photographed under a fluorescent microscope.

\section{Results}

Grailsine-Al-glycoside suppressed the proliferation of cancer cells

Grailsine-Al-glycoside strongly inhibited the proliferation of HeLa, MCF 7 , and A549 cells. The treatment of $20 \mu \mathrm{g} / \mathrm{ml}$ of Grailsine-Al-glycoside significantly inhibited the cell proliferation in those three cell lines after $48 \mathrm{hr}$ and $72 \mathrm{hr}$ while the dosage of $40 \mu \mathrm{g} / \mathrm{ml}$ had an even stronger inhibition (Figure 2). On the other hand, Grailsine-Al-glycoside could only inhibit the proliferation of HepG2 cells for up to $48 \mathrm{hr}$ at $40 \mu \mathrm{g} / \mathrm{ml}$ dosage (Figure 2).

Grailsine-Al-glycoside promoted apoptosis of cancer cells The 4 cell lines showed different apoptotic responses upon Grailsine-Al-glycoside treatment (Figure 3). Hela, A549, and MCF7 cells all had more than 2-fold increases of apoptotic cells in the presence of $20 \mu \mathrm{g} / \mathrm{ml}$ of Grailsine-Al-glycoside over that of the control (Figure 3 A, B \& D). The increase of apoptosis caused by Grailsine$\mathrm{Al}$-glycoside treatment in HepG2 cells was much more modest (Figure 3C).

\section{Grailsine-Al-glycoside induced cell cycle arrest in some} cancer cells

HeLa cells showed no cell cycle abnormalities at any concentrations of Grailsine-Al-glycoside after $36 \mathrm{hr}$ treatments. Grailsine-Al-glycoside increased the number of G2/S phase cells of A549 in a dose dependent fashion (Figure 4). MCF-7 had a higher ratio of $\mathrm{G}_{2} / \mathrm{S}$ phase cells only with Grailsine-Al-glycoside treatment at a high

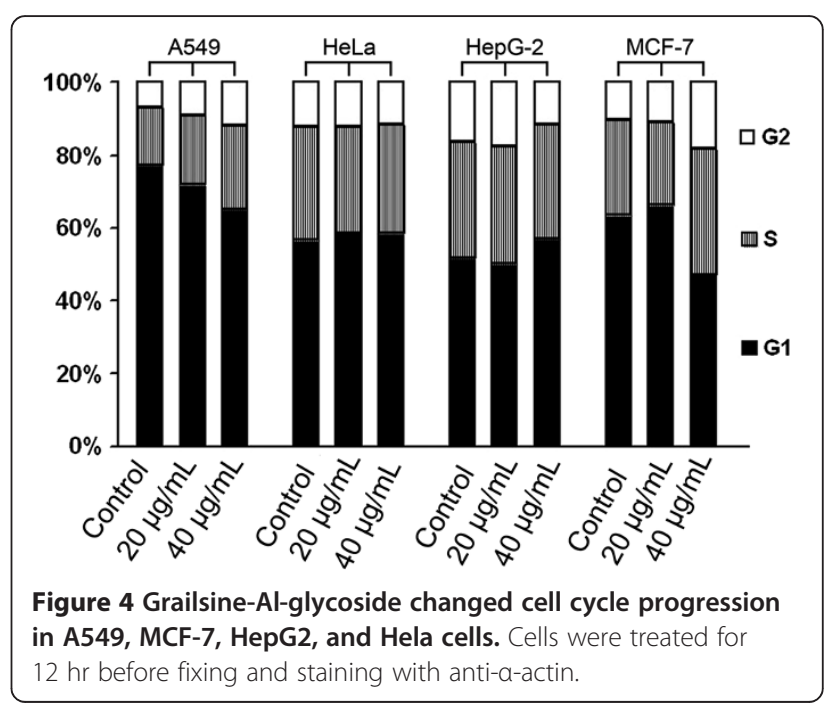




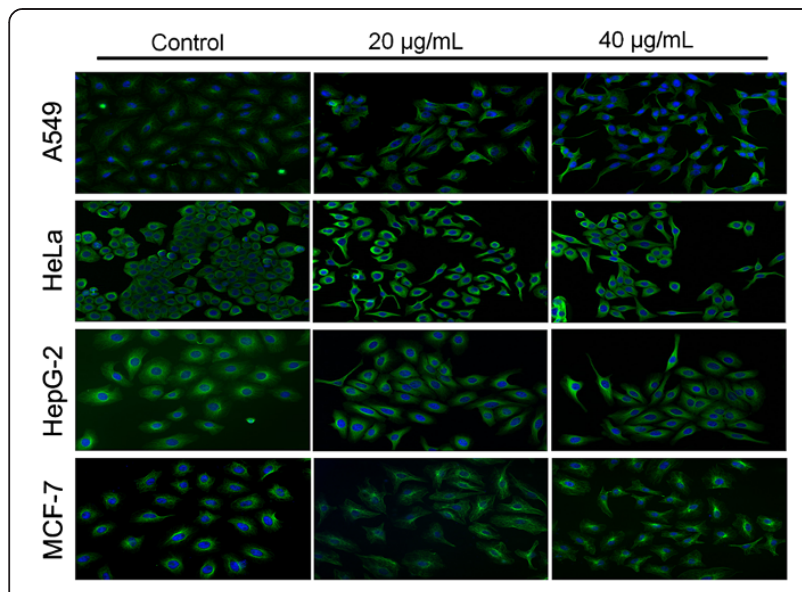

Figure 5 Grailsine-Al-glycoside caused changes of cell morphology in A549, MCF-7, HepG2, and Hela cells. Grailsine-Alglycoside treated cells were stained with anti-a-tubuin antibody and conterstained with DAPI.

concentration $(40 \mu \mathrm{g} / \mathrm{ml}$ ) (Figure 4) while HepG-2 had a higher amount of $G_{1}$ phase cells at the same high concentration (Figure 4).

\section{Cell morphology}

Grailsine-Al-glycoside-treated A549 and HepG2 cells showed a condensed cytoplasm and spindle shape with increased $\alpha$-tubulin density while MCF-7 cells had swollen cytoplasm without loss of $\alpha$-tubuin density upon the treatment of Grailsine-Al-glycoside (Figure 5). The Grailsine-Al-glycoside treatment did not induce obvious morphological change of Hela cells (Figure 5).

\section{Discussion}

Grailsine-Al-glycoside showed strong inhibitory effects on $\mathrm{ER}^{+}$human lung cancer cell line A549 and breast cell line MCF-7, by inhibiting cell proliferation and inducing apoptosis. Surprisingly, Grailsine-Al-glycoside exhibited the same inhibitory effects on $\mathrm{ER}^{-}$human cervical cell line Hela and/liver cancer cell line HepG2, indicating that Grailsine-Al-glycoside could exert its anti-cancer effects through a different pathway other than ER.

The number of HeLa cells was severely suppressed by Grailsine-Al-glyeoside ( $40 \mu \mathrm{g} / \mathrm{ml})$ due to growth inhibition and apoptosis but cells showed moderate morphological changes and no cell cycle abnormality was observed at 36 h treatment. HepG2 cells showed different changes in response to Grailsine-Al-glycoside treatment, which had modest inhibition of proliferation and increase of apoptosis but significant G1 phase arrest at a concentration of $40 \mu \mathrm{g} / \mathrm{ml}$. Such changes might be resulted from the inhibition of estrogen-related receptor $\alpha(E R R \alpha)$ [11]. ERR $\alpha$ is one of the orphan nuclear receptors which is constitutively active, and it does not respond to estradiol (E2) or natural estrogens. ERR $\alpha$ is expressed in various types of cancer, such as breast [12], endometrial [13], cervical [11], and colorectal cancers [14]. Increased ERR $\alpha$ levels are associated with a higher risk of recurrence and poor clinical outcome in breast cancer, suggesting that ERR $\alpha$ could be a negative prognostic factor [11]. Grailsine-Al-glycoside showed the ability to suppress the growth of both $E R^{+}$ breast cancers and ER ${ }^{-}$but ERR $\alpha$-expressing cancers.

Similarly, a compound called N-[(2Z)-3-(4,5-dihydro1,3-thiazol-2-yl)-1,3-thiazolidin-2-yl idene]-5H dibenzo [a, d] [7] annulen-5-amine was found inhibiting the proliferation of both $\mathrm{ER}^{+}$and $\mathrm{ER}^{-}$breast cancer cells through the inhibition of ERR $\alpha$ signaling [15]. Taken together, it can be postulated that 1) ERR $\alpha$ is a possible therapeutic target for both $\mathrm{ER}^{+}$and $\mathrm{ER}^{-}$cancers; 2) Grailsine-Alglycoside is a natural anticancer agent that may be able to inhibit ER, ERR $\alpha$, and other signaling pathways; 3) the response to Grailsine-Al-glycoside varies among cancers due to different signaling composition.

\section{Conclusions}

Grailsine-Al-glycoside from RS showed anti-cancer effects on both $\mathrm{ER}^{+}$and $\mathrm{ER}^{-}$cancer cells by inhibiting proliferation, triggering apoptosis, and / or cell cycle arrest.

\section{Abbreviations}

RS: Rhizoma Sparganii; RS-W: Aqueous extract of RS; ER: Estrogen receptor;

ERRa: Estrogen-related receptor a; MTT: 3-(4,5-dimethylthiazol-2-yl)-2,5diphenyltetrazolium bromide.

\section{Competing interests}

The authors declare that they have no competing interest.

\section{Authors' contributions}

JWZ carried out experiments, drafted the manuscript and revising it. YHW conceived the project, designed study, drafted the manuscript and revising it. Both authors have read and approved the final manuscript.

\section{Acknowledgments}

We would like to thank Hua Yang for cell culture and Ri-Shuang Bao for technical support. The authors would also like to thank Dr. Shi Lei from Chi Biotechnology for critical reading. The project is funded by Special Fund for Agro-scientific Research in the Public Interest of China 2012-2016 (201203062).

\section{Author details}

${ }^{1}$ Key Laboratory of Resource Biology and Biotechnology in Western China, College of Life Science, Northwest University, 229 Taibai Road (N), Xi'an 710069, P.R. China. ${ }^{2}$ College of Pharmacy, Shaanxi University of Chinese Medicine, Xianyang 712046, P.R. China.

Received: 22 July 2013 Accepted: 17 February 2014 Published: 3 March 2014

\section{References}

1. Acconcia F, Kumar R: Signaling regulation of genomic and nongenomic functions of estrogen receptors. Cancer Lett 2006, 238:1-14.

2. But AJ, MCNeil CM, Musgrove EA, Sutherland RL: Downstream targets of growth factor and oestrogen signalling and endocrine resistance: the potential roles of c-Myc, cyclin D1 and cyclin E. Endocr-Relat Cancer 2005, 12:47-59.

3. Gruber CJ, Tschugguel W, Schneeberger C, Huber JC: Production and actions of estrogens. New Engl J Med 2002, 346:340-352.

4. Fox EM, Bernaciak TM, Wen J, Weaver AM, Shunpike MA, Silva CM: Signal transducer and activator of transcription $5 b, c-S r c$, and epidermal growth factor receptor signaling play integral roles in estrogen-stimulated 
proliferation of estrogen receptor-positive breast cancer cells. Mol-Endocrinol 2008, 22:1781-1796.

5. Imagawa W, Pedchenko VK, Helber J, Zhang H: Hormone/growth factor interactions mediating epithelial/stromal communication in mammary gland development and carcinogenesis. J Steroid Biochem Mol Biol 2002, 80:213-230.

6. Mollerup S, Jorgensen K, Berge G, Haugen A: Expression of eatrogen receptors $\alpha$ and $\beta$ in human lung tissue and cell lines. Lung Cancer 2002, 37:153-159.

7. Osborne CK, Schiff R: Growth factor receptor cross-talk with estrogen receptor as a mechanism for tamoxifen resistance in breast cancer. Breast 2003, 12:362-367.

8. Villa E, Colantoni A, Grottola A, Ferretti I, Buttafoco P, Bertani H, Maria ND, Manenti F: Variant estrogen receptors and their role in liver disease. Mol Cell Endocrinol 2002, 193:65-69.

9. Pharmacopoeia Commission of the People's Republic of China: Pharmacopoeia of The People's Republic of China 2010. Beijing: Chemical Industry Press; 2011. Part l:11.

10. Sun J, Wei YH: A new alkaloid-aluminum glycoside isolated from rhizoma sparganii (sparganium stoloniferum buch. Ham.). J Med Plants Res 2011, 14:3128-3131.

11. Mori T, Sawada M, Kuroboshi H, Tatsumi H, Katsuyama M, Iwasaku K, Kitawaki J: Estrogen-related receptor a expression and function are associated with vascular endothelial growth factor in human cervical cancer. Int J Gynecol Cancer 2011, 21:609-615.

12. Jarzabek K, Koda M, Kozlowski L, Sulkowski S, Kottler ML, Wolczynski S: The significance of the expression of ERRalpha as a potential biomarker in breast cancer. J Steroid Biochem Mol Biol 2009, 113:127-133.

13. Watanabe A, Kinoshita Y, Hosokawa K, Mori T, Yamaguchi T, Honjo H: Function of estrogen-related receptor $a$ in human endometrial cancer. J Clin Endocrinol Metable 2006, 91:1573-1577.

14. Cavallini A, Notarnicola M, Giannini R, Montemurro S, Lorusso D, Visconti A, Minervini F, Caruso MG: Oestrogen receptor-related receptor a (ERR a) and oestrogen receptors (ER $a$ and ER $\beta$ ) exhibit different gene expression in human colorectal tumour progression. Eur J Cancer 2005, 41:1487-1494.

15. Chisamore MJ, Wilkinson HA, Flores O, Chen JD: Estrogen-related receptor-A antagonist inhibits both estrogen receptor-positive and estrogen receptor-negative breast tumor growth in mouse xenografts. Mol Cancer Ther 2009, 8:672-681.

doi:10.1186/1472-6882-14-82
Cite this article as: Zhang and Wei: Anti-cancer effects of grailsine-alglycoside isolated from Rhizoma Sparganii. BMC Complementary and Alternative Medicine 2014 14:82.

\section{Submit your next manuscript to BioMed Central and take full advantage of:}

- Convenient online submission

- Thorough peer review

- No space constraints or color figure charges

- Immediate publication on acceptance

- Inclusion in PubMed, CAS, Scopus and Google Scholar

- Research which is freely available for redistribution 